\title{
Retinal toxicity after repeated intravitreal carboplatin injection into rabbit eyes
}

\author{
Pavel Pochop ${ }^{a}$, Denisa Darsovaa , Jiri Uhlik', Jan Lestak', Jiri Kukackac, Daniela Kodetovad , Eva Klapkovac, Josef Malise, \\ Ludek Vajner ${ }^{b}$
}

\begin{abstract}
Background. The aim of this study was to assess retinal toxicity in a rabbit model after carboplatin delivered as repeated transcorneal intravitreal injection, in order to determine the highest possible safe dose for use in human retinoblastoma "seeding" tumor chemotherapy.

Methods and Results. We used six albino rabbits in an in vivo experiment and injected $0.008 \mathrm{mg}$ of carboplatin intravitreally (iv) 4 times at two-week intervals. $0.08 \mathrm{~mL}$ saline was injected into the left eye. We recorded electroretinograms (ERGs) before the first carboplatin injection and after the fourth injection. Platinum concentration was measured $1 \mathrm{~h}$ after the fifth additional injection. We found reduced dark-adapted b-wave amplitudes and, light-adapted b-wave and a-wave amplitudes. The differences between right and left eyes was significant but we found no histopathologic retinal changes.
\end{abstract}

Conclusions. $0.008 \mathrm{mg}$ of carboplatin is probably the highest possible safe dose for the treatment of retinoblastoma patients. Questionable is direct extrapolation of retinal toxicity from the rabbit eye model to the human eye.

Key words: carboplatin concentration, electroretinogram, intravitreal seeding, local treatment, rabbit, retinoblastoma

Received: July 13, 2012; Accepted: November 29, 2012; Available online: December 10, 2012

http://dx.doi.org/10.5507/bp.2012.106

${ }^{a}$ Department of Ophthalmology for Children and Adults, $2^{\text {nd }}$ Faculty of Medicine, Charles University in Prague, Czech Republic

${ }^{b}$ Department of Histology and Embryology, $2^{\text {nd }}$ Faculty of Medicine, Charles University in Prague

'Department of Clinical Biochemistry and Pathobiochemistry, $2^{\text {nd }}$ Faculty of Medicine, Charles University in Prague

${ }^{d}$ Department of Pathology and Molecular Medicine, $2^{\text {nd }}$ Faculty of Medicine, Charles University in Prague

${ }^{e}$ Department of Paediatric Haematology and Oncology, $2^{\text {nd }}$ Faculty of Medicine, Charles University in Prague

${ }^{f}$ Department of Ophthalmology, Clinic of Jan Lestak, Prague

Corresponding author: Pavel Pochop, e-mail: pavel.pochop@gmail.com

\section{INTRODUCTION}

Retinoblastoma is a childhood cancer arising from immature retinal cells in one or both eyes. Chemotherapeutics are used in treatment but vitreous seeding is a serious limiting factor in retinoblastoma therapy. Various modalities to increase intravitreal concentrations of chemotherapeutics have been tested, for example, coulomb-controlled iontophoresis ${ }^{1}$, peribulbar administration $^{2}$, cryotherapy one day before intravenous carboplatin with or without cyclosporine ${ }^{3}$ etc. Some are too complex for clinical practice or vitreous concentrations of chemotherapeutic do not reach effective levels and are unstable ${ }^{1}$. Another described treatment is intravitreal transscleral injection of chemotherapeutic agent ${ }^{4,5}$. No serious complications have been found to date but tumor dissemination in human retinoblastoma was demonstrated by subsequent fine needle biopsy or pars plana vitrectomy ${ }^{6}$. Hence, some physicians used a more difficult approach through the limbus, anterior chamber and peripheral iris for fine needle aspiration biopsy to avoid seeding tumor cells into orbital tissues ${ }^{7-9}$. This approach was also used in this experiment. We assessed possible retinal changes after transcorneal intravitreal carboplatin injection which would preclude its use in clinical practice. We chose the rabbit and we selected a dose of $0.008 \mathrm{mg}$ according to previously published data ${ }^{10,11}$, where a dose of $0.001 \mathrm{mg}$ induced no changes on electroretinograms (ERGs) and a dose of $0.01 \mathrm{mg}$ evoked significant alterations. The dose we chose was near the upper limit in order to achieve the most effective concentration.

\section{MATERIALS AND METHODS}

\section{Animals and drug delivery}

After approval by the Faculty Committee on animal welfare, New Zealand albino male specified pathogen-free (SPF) healthy rabbits (Anlab, Prague, Czech Republic) $(\mathrm{n}=6)$ received a $0.008 \mathrm{mg}$ dose of carboplatin dissolved in $0.08 \mathrm{~mL}$ of saline by unilateral transcorneal intravitreal injection into the right eye. The same volume of saline was injected into the left eye of each animal as a sham control. The same procedure was carried out 4 times at two-week intervals. Rabbits were kept under standard laboratory conditions. Ambient temperature was $20-24{ }^{\circ} \mathrm{C}$, and relative air humidity ranged from $55-60 \%$. They were anesthetized with a mixture of ketamine hydrochloride $(50 \mathrm{mg}$ / kg, Narketan 10 a.u.v. inj, Vétoquinol, Lure Cedex, France) and xylazine hydrochloride $(5 \mathrm{mg} / \mathrm{kg}$, Rometar $2 \%$ a.u.v. inj, Spofa, Prague, Czech Republic) given intramuscularly (im) before the intervention. Topical oxybu- 
procaine anesthetic eyedrops $(0.4 \%$, Benoxi gtt., Unimed Pharma, Bratislava, Slovakia) were instilled into the conjunctival sacs and the eyelids were fixed with a sterile speculum. A total of $3 \mathrm{~mL}$ of $1 \%$ povidoneiodine solution (10\% Betadine, EGIS Pharmaceuticals Ltd., Budapest, Hungary) was used for disinfection. Two months after the first injection of carboplatin, all rabbits were euthanatized by exsanguination via the carotid arteries under general anaesthesia and their eyes were processed for histopathologic examination.

Electroretinograms (ERGs) were recorded before the first and 2 weeks after the fourth injections. Electroretinographic readings consisted of a series of intensities presented under dark and light-adapted conditions according to the ISCEV protocol. Pupillary mydriasis was induced by instillation of one drop of tropicamide $0.5 \%$ (Mydrum, Chauvin Ankerpharm GmbH, Germany). After 30 min of dark adaptation, ERGs were recorded simultaneously with a skin electrode and direct corneal ERG-jet contact lens electrode ${ }^{12}$. The skin electrode was placed $1 \mathrm{~cm}$ behind the lower lid (Fig. 1). A skin electrode on the forehead served as a ground. Stimulation and recording of the ERGs were performed with the RETIscan system (Roland Consult, Brandenburg, Germany). The rod (scotopic) ERG was recorded with a white flash at an intensity of 0.01 cd.s.m- 2 and for maximal scotopic answer an intensity of $3.0 \mathrm{~cd} / \mathrm{m}^{-2} . \mathrm{s}$. The cone (photopic) ERG was recorded with the same stimuli intensities $\left(3.0 \mathrm{~cd} / \mathrm{m}^{-2} . \mathrm{s}\right)$ and background illumination of $30 \mathrm{~cd} / \mathrm{m}^{2}$. Statistical analysis was done using the software Statistica 9.1 WAN (StatSoft, Tulsa, USA). Data were compared using a t-test. $P \leq 0.05$ was considered statistically significant.

\section{Carboplatin concentration measurement}

To measure the platinum concentration, an additional, i.e. fifth, dose of the carboplatin was injected into the right eyes after the second ERG. Samples of vitreous humour were collected one hour later to verify the concentration of carboplatin in the vitreous cavity. Electrothermal

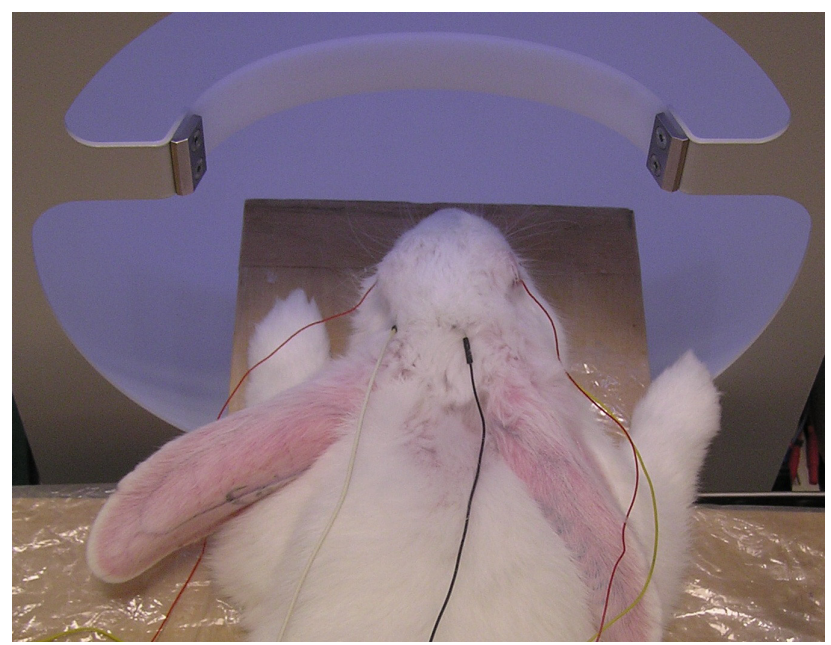

Fig. 1. Corneal ERG-jet contact lens electrode and skin electrode behind lower lid. atomic absorption spectrometry (ET-AAS) was employed to analyze the total platinum concentrations in vitreous humour after the last administration as a suitable method for carboplatin concentration determination. ET-AAS determines total Pt in fluids or tissues, including any forms of the drug subject to hydrolytic action and subsequently inactivated by irreversible binding to protein and thus rendered inactive and not cytotoxic. The platinum concentration was measured by graphite-furnace atomic absorption spectrophotometry with Zeeman background correction (Varian $220 \mathrm{Z}$, Australia). $100 \mu \mathrm{L}$ of vitreous humour was diluted 1:14 with a solution containing Triton X-100 (0.2 vol \%), antifoam A (0.2 vol \%), and deionized water. A programmable sample dispenser piped the samples and calibration standard into the furnace. Platinum determination was carried out by the standard additions method. The highest possible concentrations of carboplatin immediately after its administration were calculated according to the globe diameter.

\section{RESULTS}

All animals were followed up during the experimental period by a veterinarian. No treatment-induced weight changes were found as a sign of the general toxicity of carboplatin. One animal perished suddenly during general anesthesia before the fourth carboplatin administration. Its gross dissection showed no other cause of death. We found no structural changes on histopathologic examination of the eyes.

Statistically significant reductions in the dark-adapted b-wave ( $\mathrm{ra}$ - b) amplitudes and in the maximal scotopic answer (msa - b) amplitudes and also elevation of cone answer (Fig. 2, Tables 1 and 2) were found in carboplatin treated eyes We also found statistically significant changes in $\mathrm{ra}-\mathrm{b}, \mathrm{msa}-\mathrm{a}, \mathrm{msa}-\mathrm{b}$ and $\mathrm{ca}-\mathrm{b}$ waves in the ERGs records of control eyes (Tables 1 and 3 ). There were no structural changes on histopathologic examination. The measured average platinum concentration one hour after additional injection was $1349 \mu \mathrm{g} / \mathrm{L}$. The calculated highest possible average concentration of carboplatin according to the globe diameters was $8422 \mu \mathrm{g} / \mathrm{L}$ immediately after application of $0.008 \mathrm{mg}$ of carboplatin.

\section{DISCUSSION}

We found significant changes in the ERG records after repeated injection of $0.008 \mathrm{mg}$ of carboplatin into right eyes. Similar but more serious changes were found after single intraocular injection of higher dose (more than 0.01 $\mathrm{mg}$ ) of carboplatin ${ }^{10}$. Repeated intraocular injection of $0.05 \mathrm{mg}$ of carboplatin resulted in serious ERG changes and also structural changes - chorioretinal atrophy found by histopathologic examination ${ }^{11}$. Similar ERGs changes (elevation in ca - a) were also recorded after lead exposure $^{13}$.

Due to the effect of carboplatin on right eyes, changes in ERG records were significantly different to changes 


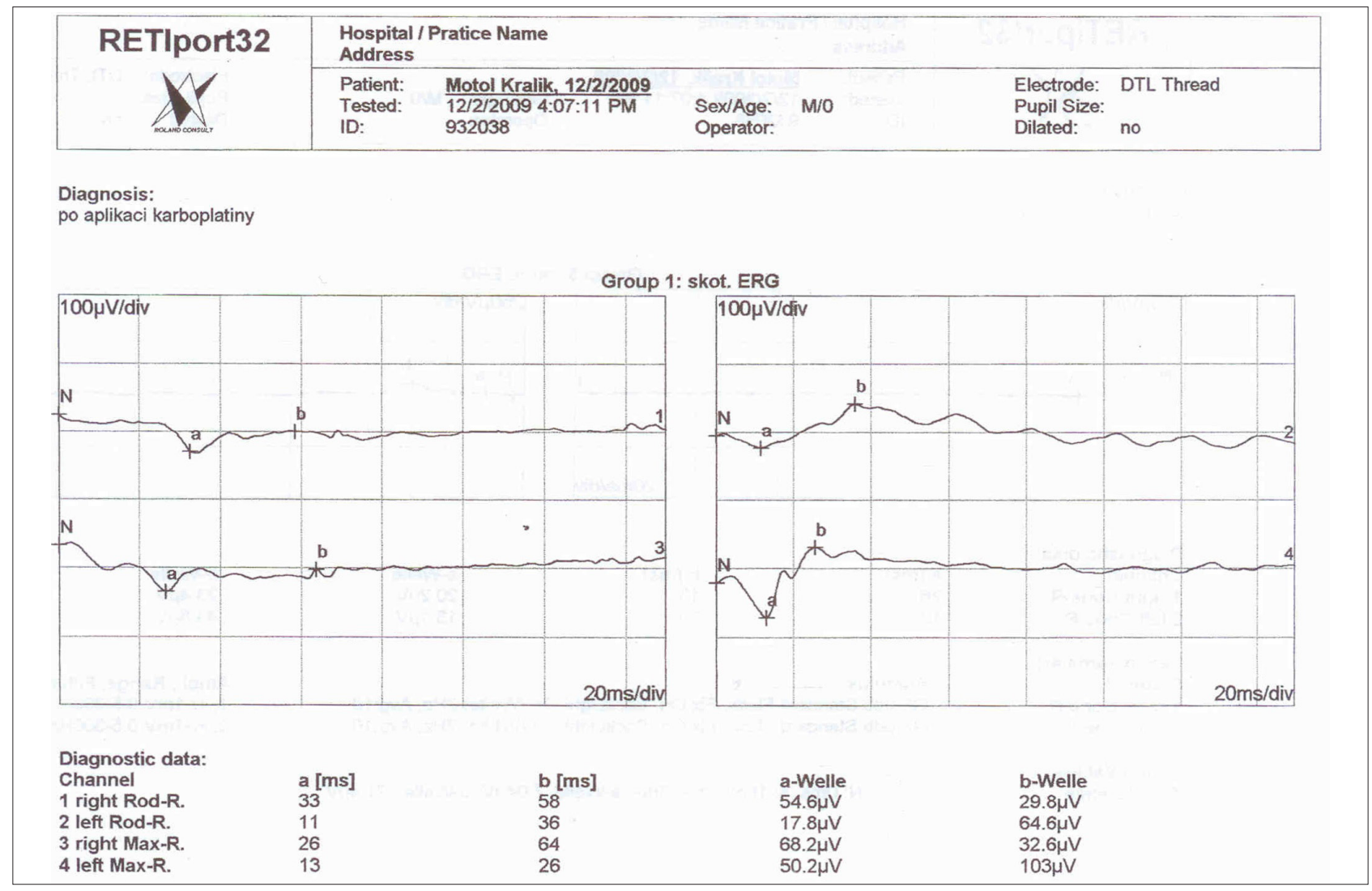

Fig. 2. ERG - Rabbit No. 932038 - Right eye after administration of the carboplatin.

Table 1. ERGs before and after administration of carboplatin (right eyes) and saline (left eyes).

\begin{tabular}{|c|c|c|c|c|c|c|}
\hline Rabbit No. & ra $-b(\mu V)$ & $\mathrm{msa}-\mathrm{a}(\mu \mathrm{V})$ & $\mathrm{msa}-\mathrm{b}(\mu \mathrm{V})$ & $\mathrm{ca}-\mathrm{a}(\mu \mathrm{V})$ & $\mathrm{ca}-\mathrm{b}(\mu \mathrm{V})$ & category \\
\hline 932038 & 132 & 108 & 230 & 5 & 87 & right $b$ \\
\hline 931018 & 91 & 105 & 114 & 2.8 & 81.2 & right $b$ \\
\hline 932012 & 132 & 139 & 233 & 5.8 & 59 & right $b$ \\
\hline 902035 & 52.7 & 87 & 145 & 0.8 & 25.2 & right $b$ \\
\hline 932337 & 94 & 84.5 & 212 & 1.4 & 48.5 & right $b$ \\
\hline 932038 & 29.8 & 68.2 & 32.6 & 20 & 23.4 & right a \\
\hline 931018 & 6.79 & 93.8 & 30.5 & 29.8 & 9.7 & right a \\
\hline 932012 & 3.32 & 117 & 88.7 & 32 & 18.8 & right a \\
\hline 902035 & 9.42 & 69.8 & 25.8 & 30.8 & 2.32 & right a \\
\hline 932337 & 1 & 62 & 33.2 & 11.8 & 13 & right a \\
\hline 932038 & 99 & 85 & 199 & 1 & 76 & left b \\
\hline 931018 & 73 & 73.5 & 96 & 5.2 & 65.7 & left $b$ \\
\hline 932012 & 72.6 & 90 & 140 & 4.68 & 64 & left $b$ \\
\hline 902035 & 69 & 78 & 158 & 3.34 & 46.5 & left $b$ \\
\hline 932337 & 72 & 40 & 130 & 0.9 & 46.6 & left $b$ \\
\hline 932038 & 64.6 & 50.2 & 103 & 13.1 & 44.8 & left a \\
\hline 931018 & 34.1 & 24.3 & 52.5 & 2.79 & 27.5 & left a \\
\hline 932012 & 35.2 & 30.5 & 70.1 & 2.7 & 39.9 & left a \\
\hline 902035 & 29.5 & 72.3 & 81.3 & 6.51 & 34.2 & left a \\
\hline 932337 & 23.7 & 21.5 & 47.5 & 6.77 & 37.1 & left a \\
\hline
\end{tabular}

Legend:

Rabbit No. $=$ rabbit number

$\mathrm{ra}-\mathrm{b}=$ rod answer, wave $\mathrm{b}$

msa $=$ maximal scotopic answer

$\mathrm{ca}=$ cone answer

right $b=$ right eye before administration

right $\mathrm{a}=$ right eye after administration

left $b=$ left eye before administration

left $\mathrm{a}=$ left eye after administration 
Table 2. Right eyes before and after administration of carboplatin.

\begin{tabular}{cccccc}
\hline & mean right b & mean right a & SD right b & SD right a & $P$ \\
\hline ra - b & 100.3400 & 9.90600 & 33.17270 & 11.14920 & $0.000415^{*}$ \\
msa - a & 104.7000 & 82.16000 & 21.84491 & 22.93138 & $0.150185^{* * *}$ \\
msa - b & 186.8000 & 42.16000 & 54.04350 & 26.17848 & $0.000657^{*}$ \\
ca - a & 3.1600 & 24.88000 & 2.18815 & 8.72995 & $0.000649^{*}$ \\
ca - b & 60.1800 & 13.44400 & 25.11259 & 8.15118 & $0.004188^{*}$ \\
\hline
\end{tabular}

$* P<0.01$

$* * *$ neglectable

Table 3. Left eyes before and after administration of saline.

\begin{tabular}{lccccc}
\hline & mean left b & mean left a & SD left b & SD left a & $P$ \\
\hline ra - b & 77.1200 & 37.30000 & 12.33175 & 15.59920 & $0.002062^{*}$ \\
msa - a & 73.3000 & 39.76000 & 19.66469 & 21.36605 & $0.032478^{* *}$ \\
msa - b & 144.6000 & 70.88000 & 37.86555 & 22.50182 & $0.005685^{*}$ \\
ca - a & 3.0240 & 6.37400 & 2.01154 & 4.23550 & $0.148806^{* * *}$ \\
ca - b & 59.7600 & 36.70000 & 12.90360 & 6.45949 & $0.007258^{*}$ \\
\hline
\end{tabular}

$* P<0.01$

$* * P<0.05$

$* * *$ neglectable

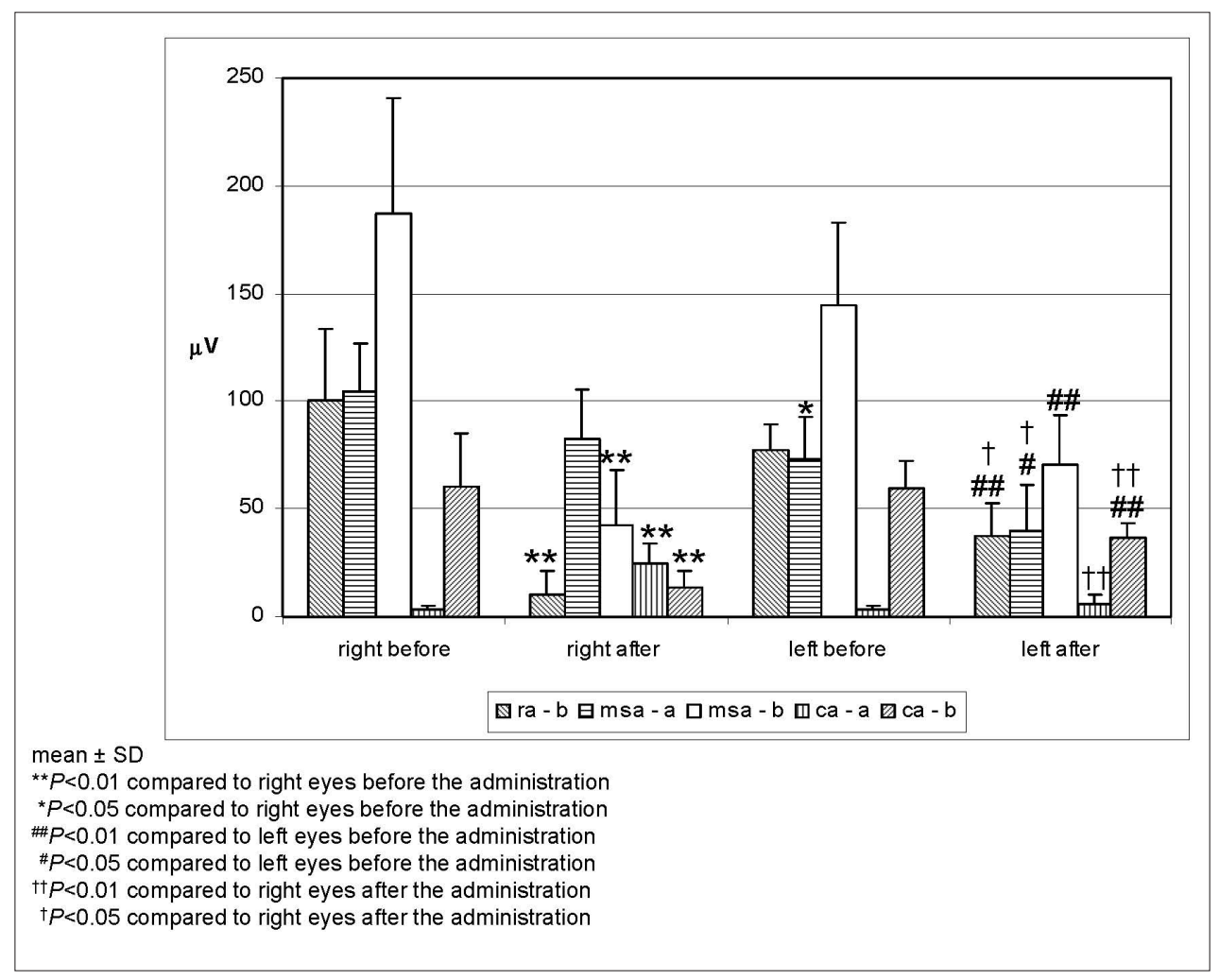

Fig. 3. Mean values of ERG before and after administration of carboplatin.

in ERGs of left eyes (Fig 3). Changes in ERGs, which were recorded in left eyes, may be caused by high intraocular pressure and transient ischemia during injection of saline ${ }^{14}$.
All changes are probably reversible and depend on the period of intraocular pressure increase ${ }^{15}$ during intravitreal injection of carboplatin and saline. Recovery of visual functions was expected as we found no structural changes 
on histopathologic examinations but an extended period of time for recovery was probably necessary ${ }^{16}$.

\section{CONCLUSION}

Intravitreal delivery of $0.008 \mathrm{mg}$ of carboplatin resulted in damage to retinal function but not structure. Thus, the changes are probably transient. The dose of carboplatin we used is probably the highest possible for the treatment of retinoblastoma patients. Questionable is, of course, the direct extrapolation of retinal toxicity from the rabbit eye model to the human eye.

\section{ACKNOWLEDGEMENT}

Authorship contributions: PP, DD: literature search; PP: manuscript writing and study design; All authors: data collection; JL, JU, LV: data analysis; JL, JU, LV, DK: data interpretation; JU, LV: statistical analysis, PP, DD: figures; PP: final approval.

Conflict of interest statement: None declared.

\section{REFERENCES}

1 Hayden BC, Jockovich ME, Murray TG, Voigt M, Milne P, Kralinger M, Feuer WJ, Hernandez E, Parel JM. Pharmacokinetics of systemic versus focal carboplatin chemotherapy in rabbit eyes: possible implication in the treatment of retinoblastoma. Invest Ophthalmol Vis Sci 2004;45:3644-9.

2. Mendelsohn ME, Abramson DH, Madlen T, Tong W, Tran HT, Dukel IJ. Intraocular concentrations of chemotherapeutic agents after systemic or local administration. Arch Ophthalmol 1998;116:1209-12.
3. Wilson TW, Chan HSL, Moselhy GM, Heydt DD Jr, Frey CM, Gallie BL. Penetration of chemotherapy into vitreous is increased by cryotherapy and cyclosporine in rabbits. Arch Ophthalmol 1996;114:1390-5.

4. Kaneko A, Suzuki S. Eye-Preservation Treatment of Retinoblastoma with Vitreous Seeding. Jpn J Clin Oncol 2003;33:601-7.

5. Velez G, Yuan P, Sung C, Tansey G, Reed GF, Chan CC, Nussenblatt RB, Robinson MR. Pharmacokinetics and Toxicity of Intravitreal Chemotherapy for Primary Intraocular Lymphoma. Arch Ophthalmol 2001;119:1518-24.

6. Shield JA, Shields CL. Intraocular Tumors: A Text and Atlas. Philadelphia, Pa: WB Saunders Co. 1992:305-91.

7. Pochop P, Darsova D, Kukacka J, Tesfaye H, Vajner L, Uhlik J, Kodetova D, Malis J, Dotrelova D. Intravitreal carboplatin concentration and area under concentration versus time curve after intravitreal and periocular delivery. Eur J Ophthalmol 2010; 20:745-51.

8. Cohen VM, Shields CL, Fruta M, Shields JA. Vitreous Seeding From Retinal Astrocytoma in Three Cases. Retina 2008;28:884-8.

9. Karcioglu ZA. Fine Needle Aspiration Biopsy (FNAB) for Retinoblastoma. Retina 2002;22:707-10.

10. Harbour JW, Murray TG, Hamasaki D, Cicciarelli N, Hernández E, Smith B, Windle J, O'Brien JM. Local carboplatin therapy in transgenic murine retinoblastoma. Invest Ophthalmol Vis Sci 1996; 37:1892-8.

11. Pochop P, Darsova D, Uhlik J, Lestak J, Kukacka J, Kodetova D, Vajner J, Malis J, Dotrelova D. Evaluation of retinal toxicity of carboplatin after repeated transcorneal intravitreal injection. In: Monduzzi editor. Proceedings of the 8th International Symposium on Ocular Pharmacology and Therapeutics - ISOPT, Rome, Italy, 2009 3-6 December; Bologna; 2009. p. 155-161.

12. Pradue MT, Hejny C, Gilbert JA, Phillips MJ, Geroski DH, Edelhauser HF. Retinal function after subconjunctival injection of carboplatin in fibrin sealant. Retina 2004; 24:776-82.

13. Rothenberg SJ, Schnaas L, Salgado-Valladares M, Casanueva E, Geller AM, Hudnell HK, Fox DA. Increased ERG a- and b-Wave Amplitudes in 7- to 10-Year-Old Children Resulting from Prenatal Lead Exposure. Invest. Ophthalmol Vis Sci 2002;43:2036-44.

14. Kremmer S, Tolksdof-Kremmer A, Stodtmeister R. Simultaneous registration of VECP and pattern ERG during artificially raised intraocular pressure. Ophthalmologica 1995;209:233-41.

15. Zhao H, Ai Y, Niu C, Guan W, Li X, Qin L. Research on Influences of Transient High IOP during LASIK on Retinal Functions and Ultrastructure. J Ophthalmol. 2009;2009:230528.

16. Polito A, Cereda M, Romanelli F, Pertile G. Macular translocation with 360 degrees retinotomy for management of retinal pigment epithelial tear: long-term results. Br J Ophthalmol 2010;95:74-8. 